\title{
Una excursió per muntanyes i valls: Gerdhard Ertl i la química de superfícies
}

Jaume Casabó, Departament de Química, Àrea de Química Inorgànica, Facultat de Ciències, UAB Joan Aliberas, IES Josep Puig i Cadafalch, Mataró, jalibera@xtec.cat

El Nobel de Química del 2007 va premiar el treball de Gerdhard Ertl sobre química de superfícies. S'exposen alguns dels seus resultats i com van ser possibles, així com la seva aplicació en catàlisis heterogènies de processos importants.

Paraules clau: química de superfícies, catalitzador, catàlisi heterogènia, adsorció, migració

La química de superfícies no és un camp que hagi proporcionat gaire premis Nobel. La llista acaba aviat:

- El 1912 es premià el treball del francès Sabatier sobre mètodes per hidrogenar compostos orgànics mitjançant metalls finament dividits.

- L'alemany Fritz Haber el rebé el 1918 per la síntesi de l'amoníac a partir dels seus elements, el conegut mètode d'Haber-Bosch, que utilitza el ferro per a la seva catàlisi. Va ser una tècnica decisiva, ja que des del 1913 permet que l'agricultura disposi d'abundants fertilitzants agrícoles nitrogenats a partir del nitrogen de l'aire. Cal dir que també fou una base per a la fabricació d'explosius.

- Cal esperar fins al 1932 perquè arribi el premi concedit al nord-americà Irving Langmuir per les seves aportacions a la química de superfícies.

- Però després de llargues dècades sense cap premi Nobel en aquest camp, el 2007 es concedeix a l'alemany Erdhard Ertl (fig. 1).

\section{Una superfície, un Iloc actiu}

En una estructura cristal-lina com la del clorur de sodi (fig. 2) és fàcil comprovar que a l'interior del cristall (fig. 3) cada ió està envoltat per sis ions de signe contrari, fent que les forces d'atracció es compensin, donant estabilitat a tota la xarxa.

Però a la superfície és diferent. Els ions que hi ha són atrets pels ions que hi ha als costats i pels de l'interior, però no des de fora. Això provoca que les superfícies dels cristalls siguin particularment reactives. Linus Pauling deia que sense elles els sòlids no serien capaços de reaccionar.

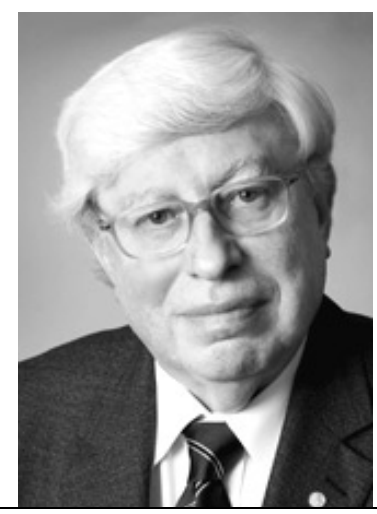

Figura 1. Erdhart Ertl, premi Nobel de Química del 2007 pels seus treballs sobre processos químics en superfícies sòlides (font).

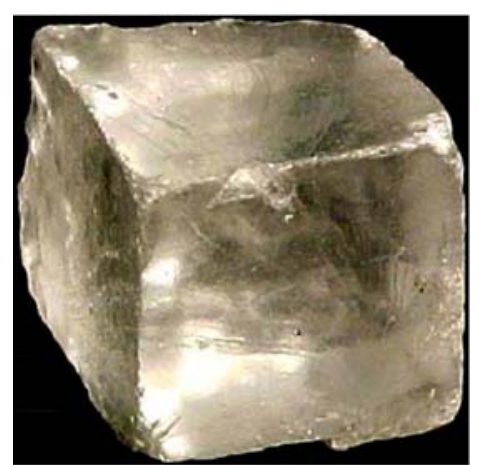

Figura 2. Cristall d'halita (clorur de sodi). 


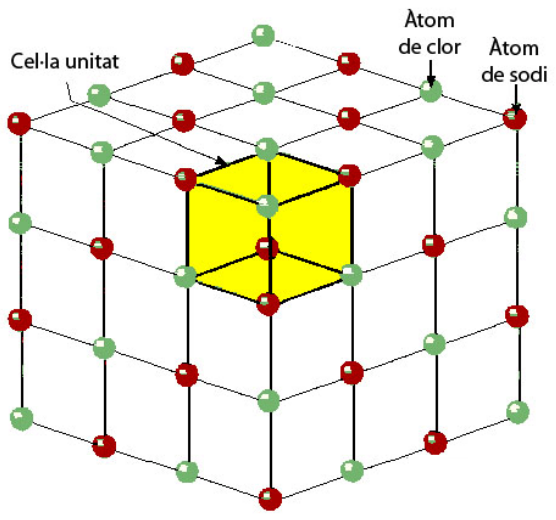

Figura 3. Reticle cristal.lí del clorur de sodi.

A més, els ions superficials es reorganitzen, com es pot veure a la imatge (fig. 4):

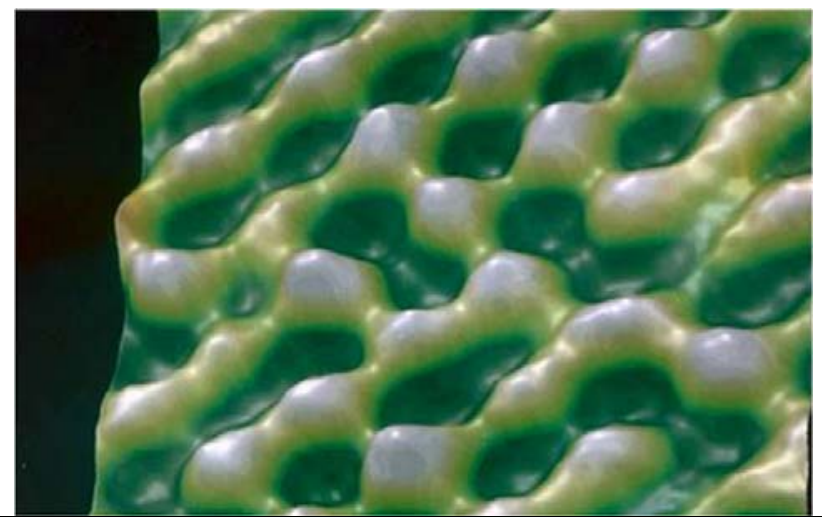

Figura 4. Imatge en fals color de la superfície d'un cristall d'una sal, realitzada amb microscopi de força atòmica. Els àtoms superficials tendeixen a formar agrupacions no regulars.

\section{El treball d'Ertl}

La concessió d'un Nobel a la química de superfícies després de tants anys de sequera té la seva explicació. Han estat necessaris molts avenços en instrumentació $\mathrm{i}$ en mètodes de recerca per poder aconseguir de progressar en aquest camp del coneixement.

El gran problema és evitar interaccions indesitjades sobre la superfície -una superfície tan activa que qualsevol gas s'hi adhereix-; és per això que era necessari obtenir un nivell de buit suficient, un buit ultra alt (entre $100 \mathrm{nPa}$ i $100 \mathrm{pPa}$ ). Fins que no hi hagué tècniques adequades per poder fer i mantenir un buit tan alt, aquest estudi no va ser possible.

Durant les dècades recents s'han anat creant instruments que fan possible l'estudi de la dinàmica dels processos que es desenvolupen en les superfícies. Un d'aquests instruments és el microscopi electrònic de fotoemissió (fig. 5).

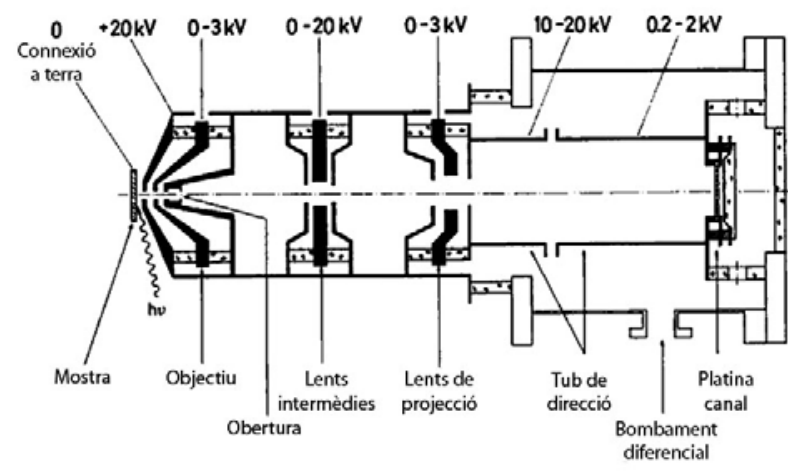

Figura 5. Microscopi electrònic de fotoemissió.

Es tracta d'un microscopi electrònic modificat, que permet observar en directe el que succeeix a la superfície de la mostra. Per aconseguir-ho s'il.lumina la mostra amb llum ultraviolada, provocant l'emissió d'electrons, que mitjançant el microscopi electrònic acaben donant una imatge en moviment (fig. 6) del que està passant a la superfície estudiada.

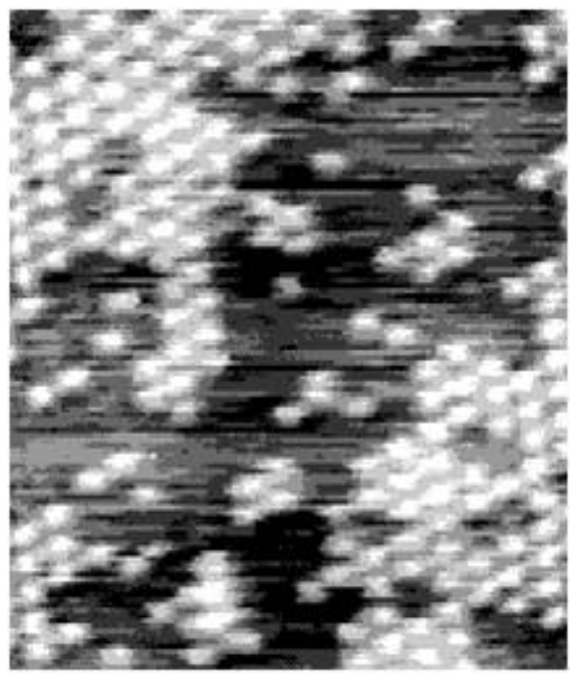

Figura 6. Fotograma d'una pel-lícula que mostra la migració d'àtoms, que apareixen de color blanc, damunt d'una superfície. (En moviment: font)

La contribució d'Ertl a la química de superfícies consisteix en una llarga sèrie d'estudis de processos químics en superfícies, realitzats tant des del camp experimental com del teòric, de forma complementària. Treballar en una institució alemanya tan potent com l'Institut Max Planck, li ha permès 
disposar d'uns recursos experimentals que no són a l'abast de qualsevol.

A més del microscopi òptic de fotoemissió que ja hem comentat, també ha utilitzat tècniques modernes com l'espectroscòpia electrònica de transformada de Fourier, l'espectroscòpia d'alta resolució de pèrdua d'energia electrònica, la difracció d'electrons de baixa energia, l'espectroscòpia de masses d'ió secundari, l'espectroscòpia electrònica ultraviolada o, com ja hem dit, els sistemes de buit ultra alt.

Amb ells Ertl ha pogut estudiar sistemàticament els processos involucrats en determinades reaccions, com la reacció de deshidrogenació de l'etilè per produir acetilè (fig. 7), o el detall del procés de Haber-Bosch per a l'obtenció d'amoníac (fig. 8), un procés conegut des de 1913 , però que no havia estat explicat.

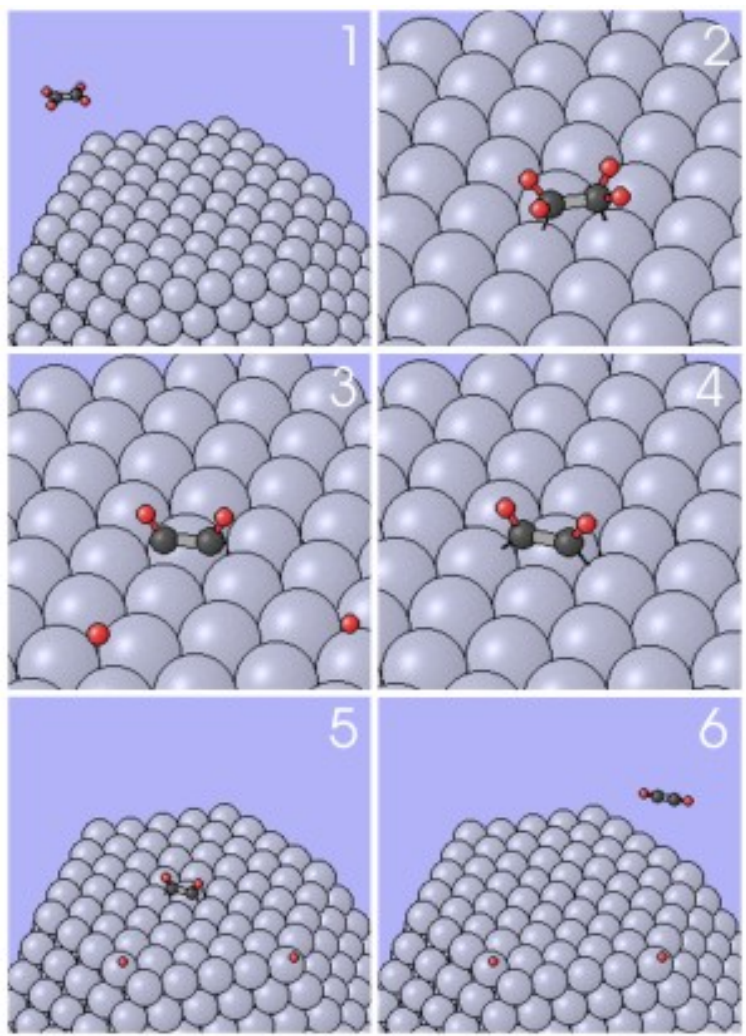

Figura 7. Reacció de deshidrogenació de l'etilè per produir acetilè, catalitzat per una superfície de níquel. L'hidrogen queda adherit a la superfície, motiu pel qual cal regenerar el catalitzador cada cert temps. (En moviment: font).

Mentre que la reacció entre l'hidrogen i el nitrogen gasosos implica una energia d'activació molt gran, el mateix procés, catalitzat per una superfície de ferro, és molt més assequible, tant pel que fa al condicionant energètic com a l'entròpic. Ertl va po- der descriure'n el mecanisme i l'energia que requeria cadascun dels passos, basant-se en els paràmetres de la superfície (fig. 9), aclarint així diversos mecanismes (fig. 10).

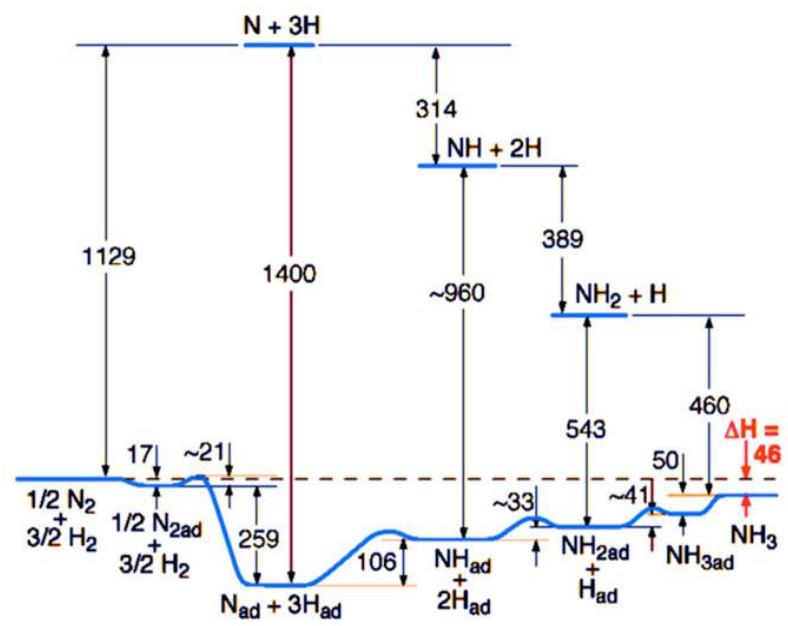

Figura 8. El procés de Haber-Bosch (ruta inferior), entre espècies adherides a la superfície, pràcticament no necessita energia d'activació, mentre que la reacció sense catalitzador (ruta superior) requereix una energia enorme (font).

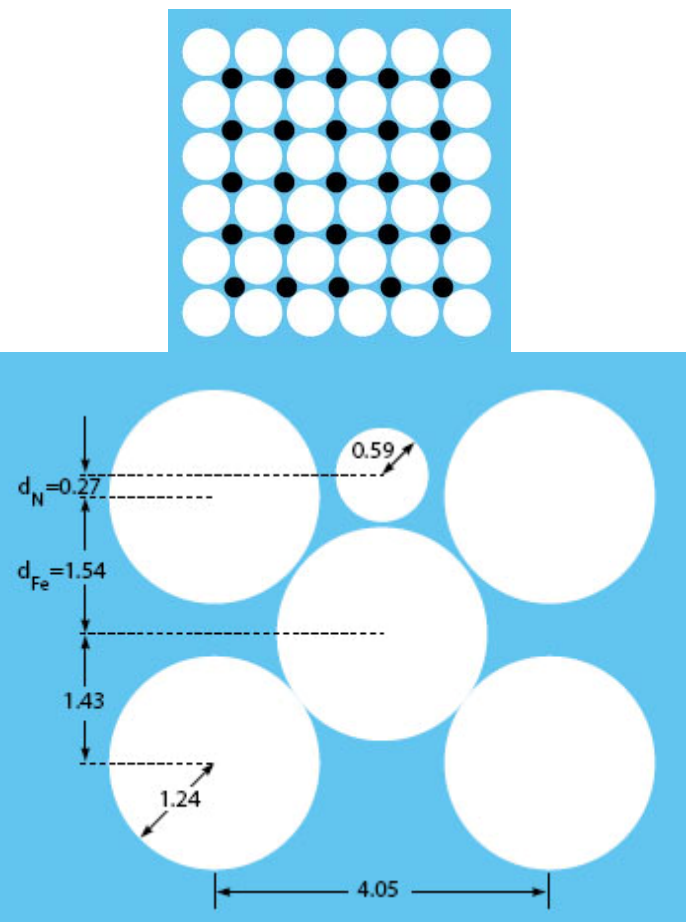

Figura 9. El diagrama de dalt mostra la ubicació dels àtoms de nitrogen (negres) sobre la superfície d'àtoms de ferro (blancs). A sota, la mateixa situació vista de costat, indicant alguns dels seus paràmetres: els cercles més grans són àtoms de ferro i els petits, de nitrogen (font). 


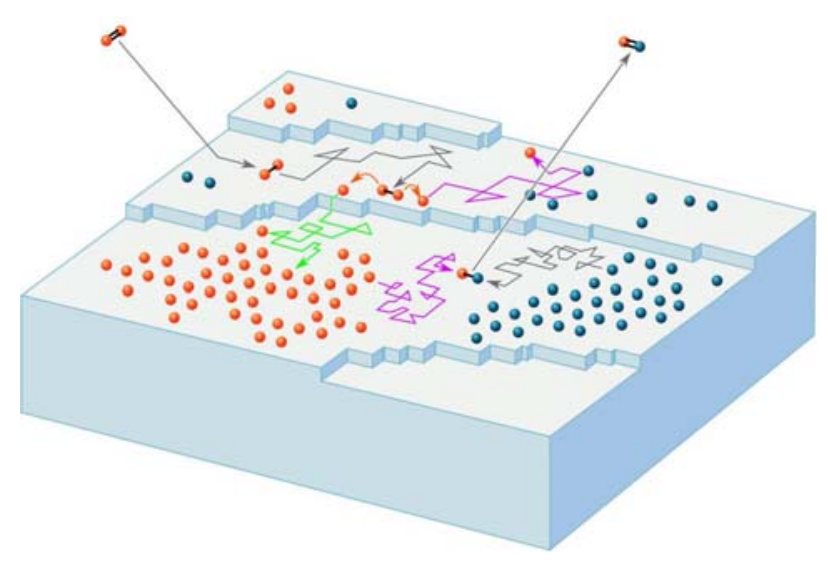

Figura 10. Diagrama mostrant alguns dels processos implicats en la reacció entre dos gasos sobre una superfície, incloent l'adsorció, dissociació, migració, reacció i alliberament de la superfície (font).

Per altra banda, el tractament de les seves imatges ha donat Iloc a resultats ben atractius (fig. 11).

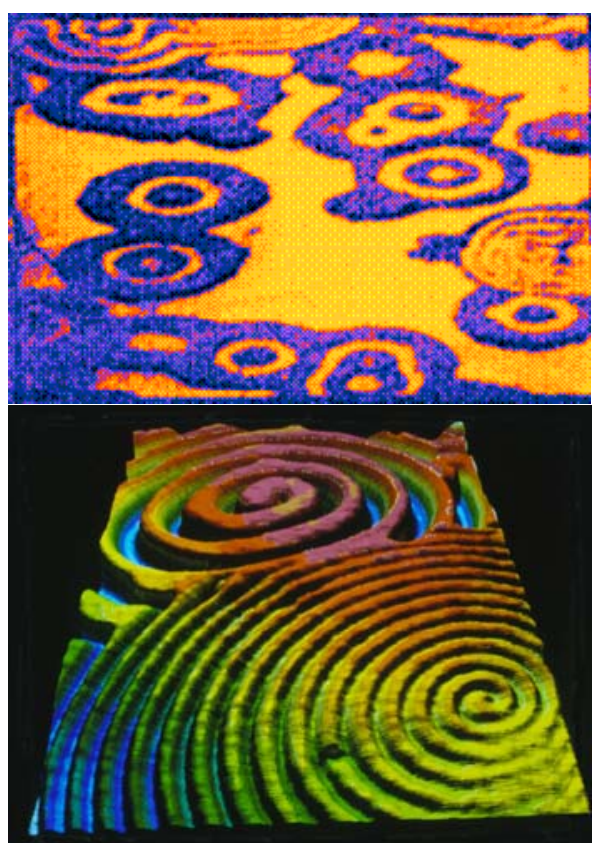

Figura 11. Imatges en fals color de processos oscil-lants sobre una superfície (font).

\section{Una estirada d'orelles}

Håkan Wennerström, un dels membres del comitè Nobel de química que va decidir el premi, afirmava:
"Les investigacions s'han realitzat amb una gran elegància en el seu aspecte experimental. El treball es caracteritza per l'ambició d'utilitzar sempre el mètode més escaient per resoldre el problema entre mans. Ertl no es conforma mai amb una observació interessant però aïllada."

No és difícil veure en aquestes darreres paraules un advertiment metodològic contra les presses per publicar resultats poc comprovats.

Immediatament vénen a la memòria casos com els de la fusió freda (en un procés a temperatura ambient els semblava detectar emissió de neutrons, cosa que indicaria que s'estava produint la fusió nuclear!) o el d'una pretesa separació d'isòmers per mètodes magnètics (que hauria estat una gran notícia per a la indústria farmacèutica).

Efectivament, el treball d'Ertl va ser molt pacient. Tot i els recursos de què disposava, li va caldre molt de treball per arribar a obtenir resultats clars i reproduïbles.

\section{La catàlisi heterogènia, present en fenòmens d'importància}

El tractor de la figura 12 exemplifica algunes de les utilitzacions que actualment té la catàlisi heterogènia (aquella en la qual el catalitzador és en una fase diferent que els reactius, com és el cas de reaccions gasoses catalitzades per una superfície sòlida):

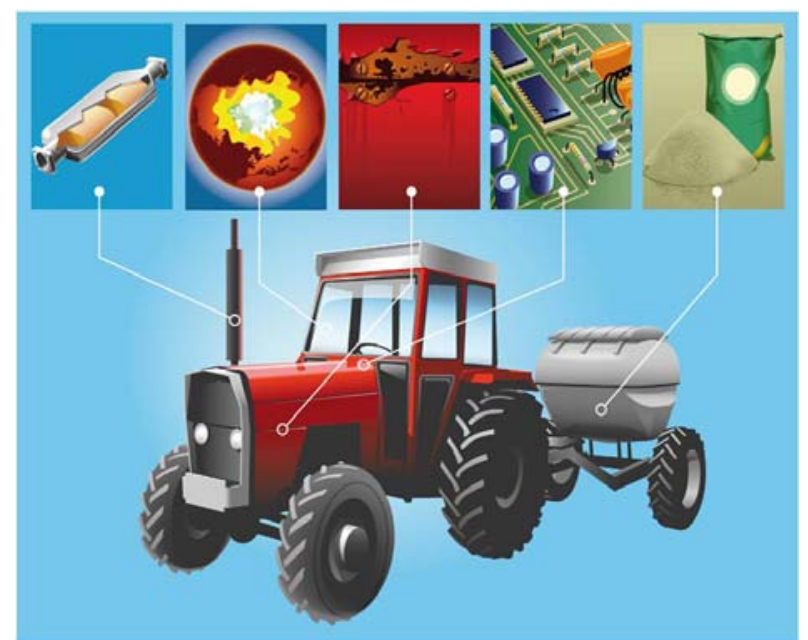

Figura 12. Processos de catàlisi heterogènia relacionats amb el treball agrícola. D'esquerra a dreta: a) tub d'escapament; b) reducció de la capa d'ozó; c) rovellament de la xapa; d) semiconductors dels circuits electrònics; e) fertilitzants artificials (font). 
a) En un tub d'escapament s'utilitza platí per catalitzar l'oxidació del $\mathrm{CO}$ en $\mathrm{CO}_{2}$ (fig. 13).

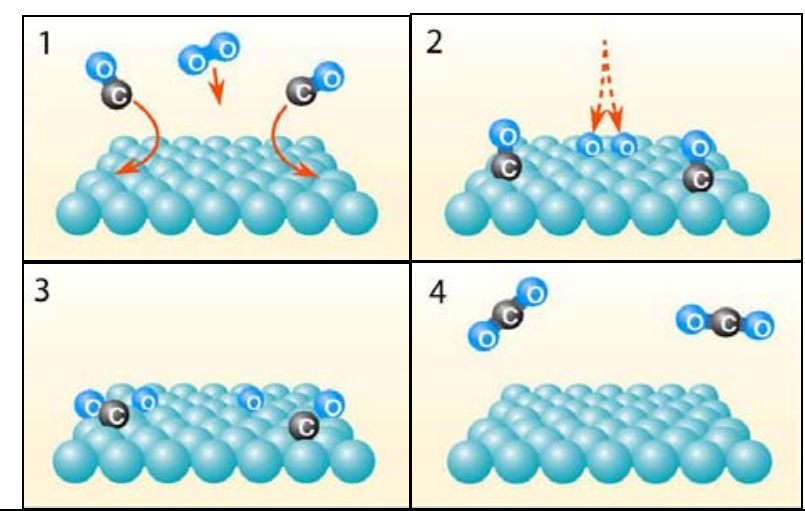

Figura 13. Reacció que transcorre a la superfície del catalitzador d'un tub d'escapament: el CO reacciona amb oxigen per produir $\mathrm{CO}_{2}$ (font). b) Un escapament de freó de l'aire condicionat acabarà reduint l'ozó estratosfèric al reaccionar amb ell sobre la superfície de cristalls de gel de l'estratosfera.

c) El rovellament es produeix quan una superfície de ferro queda exposada a l'oxigen de l'aire.

d) La indústria electrònica utilitza reaccions sobre superfícies per fabricar components semiconductors.

e) Els fertilitzants artificials es produeixen amb amoni fabricat a partir d'hidrogen i nitrogen sobre una superfície de ferro.

Fins i tot es poden produir combustibles renovables per processos basats en la catàlisi sobre superfícies.

Gràcies al treball d'Ertl i del seu equip, tots aquests fenòmens superficials ens resulten ara força més comprensibles. 